\title{
Effect of hand reflexology on anxiety and physiological variables among patients hospitalized in the cardiac care unit: A randomized placebo controlled clinical trial
}

\author{
Zohre Rahmani $^{1}$, Nahid Rejeh*2, Majideh Heravi-Karimooi ${ }^{1}$, Seyed Davood Tadrisi ${ }^{3}$, Mojtaba Vaismoradi ${ }^{4}$ \\ ${ }^{1}$ Department of Nursing, Faculty of Nursing and Midwifery, Shahed University, Tehran, Iran \\ ${ }^{2}$ Elderly Care Research Center, Department of Nursing, Faculty of Nursing and Midwifery, Shahed University, Tehran, Iran \\ ${ }^{3}$ Faculty of Nursing, Baqiyatallah University of Medical Sciences, Tehran, Iran \\ ${ }^{4}$ Faculty of Nursing and Health Sciences, Nord University, Bodø, Norway
}

Received: September 20, 2017

Accepted: November 21, 2017

Online Published: November 27, 2017

DOI: 10.5430/jnep.v8n4p35

URL: https://doi.org/10.5430/jnep.v8n4p35

\begin{abstract}
Background and objective: Admission to the cardiac care unit may cause physiological and psychological problems in patients. This study aimed to investigate the effect of hand reflexology on anxiety and physiological variables among female patients with acute coronary syndrome hospitalized in the cardiac care unit.

Methods: This randomized placebo controlled clinical trial was conducted on 90 female patients hospitalized in the cardiac care unit in an urban area of Iran. The patients were chosen using a convenient sampling method and then were randomly assigned into intervention $(n=45)$ and placebo $(n=45)$ groups. While the intervention group received hand reflexology for 20 minutes, the placebo group received a simple touch of hand without the stimulation of reflexology points. Demographic data was collected at the beginning of the study using face-to-face interviews with the patients. The anxiety level was assessed using the Spielberger's State-Trait Anxiety Inventory (STAI) immediately after the intervention and $30 \mathrm{~min}$ after the intervention. Also, physiological variables including respiratory rate, heart rate, blood pressure and oxygen saturation were measured before, immediately after the intervention and 30 minutes after the intervention. Descriptive and inferential statistics were used for data analysis.

Results: There was no statistically significant differences between the intervention and placebo groups before the intervention $(p>.05)$. The anxiety level in the intervention group was significantly lower than that of the placebo group immediately after the intervention and 30 minutes after the intervention $(p<.05, \eta=0.090)$. However, no statistically significant differences in physiological variables between the groups were observed $(p>.05)$.

Conclusions: Hand reflexology influenced the level of anxiety. Therefore, nurses can use hand reflexology as a method for reducing patients' anxiety along with other nursing interventions.
\end{abstract}

Key Words: Anxiety, Acute coronary syndrome, Physiological variables, Cardiac care unit, Hand reflexology

\footnotetext{
*Correspondence: Nahid Rejeh; Email: reje@ shahed.ac.ir; Address: Department of Nursing, Faculty of Nursing and Midwifery, Shahed University (opposite Holy Shrine of Imam Khomeini-Khalij Fars Expressway, Postal/zip code: 3319118651), Tehran. Iran.
} 


\section{INTRODUCTION}

Most patients with coronary heart diseases experience many emotional and psychological problems in the early days of admission to the cardiac care unit (CCU). ${ }^{[1]}$ One of the nursing diagnoses for such patients is anxiety, which is considered a risk factor for coronary artery diseases. ${ }^{[2]}$ It is believed that more than $42 \%$ of patients with cardiac diseases, $50 \%$ of patients with acute coronary syndrome (ACS) and 63\% of patients with heart failure experience anxiety. ${ }^{[3]}$ Anxiety influences the functions of all body parts and can increase the risk of a subsequent heart attack. Anxiety has negative effects on patients with ischemic heart diseases. ${ }^{[4]}$ Anxiety influences the nervous system, endocrine glands and the immune system. Therefore, it can cause disturbances in the cardiac rhythm and lead to cardiac ischemia, heart failure, delirium and delayed recovery from infections. ${ }^{[5]}$

The process of patient transfer to the CCU increases anxiety in these patients. 'Transfer anxiety' has been accepted as a diagnosis in 1992 by the North America Nursing Diagnosis Association. Many patients have physical issues and symptoms of anxiety after transfer from the CCU to the general care unit. ${ }^{[6]}$ Factors such as being hospitalized in a stressful environment, a lack of awareness of the disease process, fear of problems that may arise in the future for patients, carrying out cardiopulmonary resuscitations for other patients, patients' mortality rate and sleep disturbances contribute to the development of anxiety in patients admitted to the CCU. ${ }^{[7]}$

An increase in the level of anxiety has a negative effect on patient's healing and recovery; e.g., it increases the duration of hospitalization and leads to patient's death. ${ }^{[8]}$ Watkins et al.'s study showed that anxiety was an important factor in patients' mortality after a cardiovascular event. ${ }^{[9]}$ Reducing patients' anxiety as a nursing intervention can reduce the sympathetic response to anxiety in patients. Reducing the sympathetic stimulation reduces heart rate, pain and other symptoms related to ischemia. ${ }^{[10]}$ There are various pharmacological and non-pharmacological methods for reducing anxiety. ${ }^{[11]}$ Drug-related complications affect patients' consciousness and cognition and increase the risk of drug dependence and addiction. ${ }^{[12]}$ Given the consequences and side effects of drugs, it is needed to low cost and safe methods for reducing patients' anxiety and preserving their hemodynamic stability. ${ }^{[13]}$ Non-pharmacological interventions such as distraction, relaxing music, relaxation techniques, biofeedback and massage therapy are used informally by nurses as measures for reducing patients' anxiety. ${ }^{[14]}$

Reflexology as a common method of complementary therapy ${ }^{[15]}$ is considered a hand massage therapy. ${ }^{[16]}$ It is based on the idea that each body organ has a corresponding reflec- tion region on feet, hands and ears as the mirror of the body. Stimulating particular reflexes in these areas affects related organs and systems. ${ }^{[17]}$ Most studies showed that reflexology caused deep relaxation, body and mind balance, reduced stress symptoms and created good feelings in patients. ${ }^{[18]}$ The theory of reflexology is based on the principle that energy flows through vertical zones throughout body from organs toward the head. ${ }^{[19]}$ Therefore, massage and stimulation of nerves cause relaxation, reduce tension and as a result returns balance in the body. ${ }^{[20]}$ Some studies confirmed the effect of reflexology on anxiety and physiological parameters. ${ }^{[21]}$ For instance, Farahani et al. examined the effect of hand massage on anxiety and physiological indicators on 60 patients before the cataract surgery. ${ }^{[22]}$ A reduction of anxiety and an improvement of physiological indices prior the surgery were reported. ${ }^{[22]}$ Nazari et al. examined the effect of hand massage on the reduction of anxiety among patients undergoing the ophthalmology surgery using local anesthesia. ${ }^{[23]}$ Brand et al. using a quasi-experimental study assessed the effect of hand massage on patients' anxiety among patients undergoing the outpatient surgery. ${ }^{[24]}$ They showed a significant difference in the level of anxiety between hand massage and control groups and believed that hand massage effectively reduced anxiety. ${ }^{[23,24]}$

Studies have also been conducted on the effects of hand massage among patients with heart diseases. Hyun et al. reported that hand massage reduced anxiety in patients with ischemic heart diseases. ${ }^{[25]}$ Mei et al. and Heidari et al. focused on the reduction of anxiety among patients with cardiac catheterization using hand massage and achieved different results in terms of the effect size of the intervention. ${ }^{[26,27]}$ On the other hand, Wang and Keck used the massaging of organs (feet and hands) and showed a significant reduction in physiological variables including the pulse rate and respiratory rate. ${ }^{[28]}$ Combron et al. also showed the effect of hand massage on the reduction of systolic blood pressure and the increase of diastolic blood pressure. ${ }^{[29]}$ Jones et al. in two studies showed that reflexology had no effect on physiological parameters in healthy volunteers as well as in patients with heart failure. ${ }^{[30,31]}$ Given the differences in the effectiveness and use of reflexology among healthcare staff, there was a need to study the effect of reflexology on patients admitted to the CCU. Therefore, the present study aimed to investigate the effect of hand reflexology on anxiety and physiological variables among patients with ACS hospitalized in the CCU.

\section{Methods}

\subsection{Design and sample}

This randomized placebo trial was conducted in the CCU of a large referral teaching hospital in an urban area of Iran. The 
sample consisted of female patients with ACS admitted to the CCU. Given the number of samples in a previous study, ${ }^{[32]}$ 95\% confidence interval $(\alpha=5 \%)$, power of $90 \%(\beta=10 \%)$ and $10 \%$ dropout, the number of samples was determined 45 patients in each group using the following sampling formula: $\mathrm{n}=(\mathrm{z}[1-\alpha / 2]+\mathrm{z}[1-\beta])^{2}\left(\mathrm{~S}_{1}^{2}+\mathrm{S}_{2}^{2}\right) / \Delta \mathrm{M}^{2}$

\subsection{Inclusion and exclusion criteria}

Female patients with ACS were enrolled on the second day of admission. It was noted that to prevent the effect of gender on the anxiety level, only female patients were included in this study. The patients were selected using a convenient sampling method and then were assigned to intervention and placebo groups using a random sampling method. The assignments to the groups were performed using a block random method with the ratio of $4: 4$ by a staff nurse who was unaware of the patients' assignments using a table of random numbers. Also, the size of blocks was not announced during this process to prevent any selection bias.

Inclusion criteria were female gender, the age group 18-60 years, not currently pregnant, having no cardiac pacemaker, no addiction to alcohol or drugs, no routine use of anxiolytic drugs, no sensory impairment, no infection or ulcers or skin diseases in the hands, and no history of reflexology massage. Those patients who were unwilling to continue the study, transferred to another unit, received warfarin, or had any contraindication to continue the intervention were excluded from the study.

\subsection{Ethical considerations}

The study was carried out from March 2016 to July 2017. Prior to the study, the research proposal was approved by the ethic committee with which the authors worked (Decree code: IR.Shahed.REC.1395.171). The research protocol was registered in the Iranian clinical trial system with the code IRCT201703287529N13. The purpose and method of the study were described to the patients. Also, their confidentiality throughout the study was ensured and informed consent was obtained from those who willingly agreed to take part in this study.

\subsection{Procedure}

The list of female patients with ACS and hospitalized in the $\mathrm{CCU}$ was provided to the investigators. Using the blocking and table of random numbers, the patients were assigned into intervention and placebo groups. In the intervention group, a female researcher who had received appropriate education and training in reflexology drew curtains around the patient to provide privacy. The researcher sat on a chair near the patient and greased the patient's hand with sweet

Published by Sciedu Press odorless almond oil for one minute. Next, according to Ingham's method, ${ }^{[32]}$ hand reflexology was performed on the right hand and then left hand for 20 minutes. The researcher performed the massage with her thumb, started from the forearm, moved to the wrist, palm, back of the hand and lastly fingers. In the intervention group, the patient received two minutes of reflexology massage at the three reflexology points for the pituitary gland, heart and solar plexus (six minutes in total), using a stimulation with a moderate pressure. The solar plexus, pituitary and heart points were located by the researcher. She exerted firm downward pressure with her thumb at the points for two minutes in every area. The pressure was regulated so that the upper thumb was white, but patients did not feel any pain. Subsequently, a circular rotational massage was applied to the specific points. The same procedures were performed on the other hand. In the placebo group, conditions similar to the intervention group were created, but the simple touch of hand without stimulation of the reflexology points was applied. It was noted that in both groups, the massage was performed exclusively by a female person.

The procedure environment for both groups was to minimize unnecessary disturbance and promote rest through dimming the lights (unless contraindicated), closing curtains, partially posting 'Patients Are at Rest' and Please Do Not Disturb' signs. Nurses and medical staff were instructed not to disturb the patient during the intervention or rest period unless it was imperative. In all cases, efforts were made by the staff to proceed silently within the ward to prevent any disturbance.

\subsection{Data collection}

Data was gathered using a questionnaire consisting of three parts. The demographic data form was filled out using patient's medical records or interviewing the patients. The Spielberger's State-Trait Anxiety Inventory (STAI), and the checklist of physiological variables were also used.

The STAI was developed by Spielberger in $1970 .{ }^{[33]}$ It had 40 items and two anxiety parts that were completed through interviews with the patients. The STAI as a self-assessment questionnaire was consisted of short items and contained two separate scales consisting of a total of 40 items. The first part (1-20 items) was related to State Anxiety and the second part (questions 21-40) was about Trait Anxiety. The State Anxiety scale referred to an individual to describe how he/she felt at a given moment and in certain circumstances and describe her/his feelings about the situation. The Trait Anxiety scale referred to an individual to describe how he/she felt usually across typical situations that everyone experienced on a daily basis. The result was based on the score of positive answers from very low (4), low (3), high (2) very high (1). However, 
negative questions had reverse scoring, i.e. very low (1), low (2), high (3) and very high (4). The total score was between 40 (the lowest possible anxiety) and 120 (the highest possible anxiety). A score of 40-79 indicated mild anxiety, 80-119 indicated moderate anxiety and 120-160 showed severe anxiety. ${ }^{[34]}$ Mahram (1994) confirmed validity and reliability of the Farsi version of the STAI. ${ }^{[35]}$

The data was collected before, immediately after the intervention and 30 minutes after the intervention. In addition to recording the level of anxiety, respiratory rate (RR), heart rate (HR), systolic blood pressure (SBP), diastolic blood pressure (DBP) and mean arterial pressure (MAP) were measured using 800 SI digital monitors produced by the Poyandegan Rah Saadat $\mathrm{Co} R$. Moreover, oxygen saturation $\left(\mathrm{SPO}_{2}\right)$ was measured using a pulse oximetry device.

This study was doubled-blinded, so that the patients were blinded to the intervention and were unaware of the groups' assignments. Also, the data was collected by a staff nurse in the CCU who was blind to allocation of the groups. Ad- ditionally, the statistical analyzer was also not aware of the patients' allocation.

\subsection{Data analysis}

Descriptive and inferential statistics were used for data analysis. Repeated measure ANOVA, Fisher's Exact, MannWhitney $\mathrm{U}, t$-Test and Chi-Square test were performed via the SPSS software version 22 (SPSS; SPSS Inc., Chicago, IL, USA). The Kolmogorov-Smirnov test was performed to investigate the normality of data. The significance level was considered $p<.05$.

\section{RESUltS}

The demographic data of the patients were described in Table 1. All female patients with ACS in the ward were included in this study. They also suffered from other diseases including hypertension and diabetes mellitus. No statistically significant differences between the groups were reported in terms of demographic characteristics $(p>.05)$.

Table 1. Comparisons of demographic characteristics between the groups immediately after and 30 minutes after the intervention

\begin{tabular}{|c|c|c|c|c|}
\hline \multicolumn{2}{|c|}{ Demographic characteristics of the patients } & $\begin{array}{l}\text { Intervention } \\
(\mathrm{n}=45)\end{array}$ & $\begin{array}{l}\text { Placebo } \\
(n=45)\end{array}$ & Statistical analysis, $p$-value \\
\hline \multicolumn{2}{|l|}{$\begin{array}{l}\text { Age }(\text { year }) \\
(\text { Mean } \pm \mathrm{SD})\end{array}$} & $50.16 \pm 6.87$ & $48.87 \pm 6.72$ & $\begin{array}{l}\text { Independent } t \text {-test, } \\
t=.89, \mathrm{df}=88, p=.37\end{array}$ \\
\hline \multicolumn{2}{|c|}{$\begin{array}{l}\text { Length of hospitalization (day) } \\
\text { (Mean } \pm \text { SD) }\end{array}$} & $2.57 \pm 1.05$ & $2.73 \pm 1.05$ & $\begin{array}{l}\text { Mann-Whitney } \mathrm{U} \\
\mathrm{Mdn}=2, \mathrm{u}=1012.50, p=.99\end{array}$ \\
\hline \multirow{5}{*}{$\begin{array}{l}\text { Education level, } \\
\mathrm{N}(\%)\end{array}$} & Illiterate & $16(35.6)$ & $11(24.4)$ & \multirow{5}{*}{$\begin{array}{l}\text { Chi-Square test, } \\
\chi^{2}=1.34, \mathrm{df}=3, p=.71\end{array}$} \\
\hline & Primary school & $15(33.3)$ & $18(40)$ & \\
\hline & Secondary school & $9(20)$ & $10(22.2)$ & \\
\hline & High school & $5(11.1)$ & $6(13.3)$ & \\
\hline & Total & $45(100)$ & $45(100)$ & \\
\hline \multirow{3}{*}{$\begin{array}{l}\text { Marital status, } \\
\mathrm{n}(\%)\end{array}$} & Married & $38(84.4)$ & $39(86.7)$ & \multirow{3}{*}{$\begin{array}{l}\text { Fisher's Exact test, } \\
p=.99\end{array}$} \\
\hline & Widow & $7(15.6)$ & $6(13.3)$ & \\
\hline & Total & $45(100)$ & $45(100)$ & \\
\hline \multirow{3}{*}{$\begin{array}{l}\text { Employment status, } \\
\text { n (\%) }\end{array}$} & Employed & $1(2.2)$ & $6(13.3)$ & \multirow{3}{*}{$\begin{array}{l}\text { Fisher's Exact test, } \\
p=.11\end{array}$} \\
\hline & Housewife & $44(97.3)$ & $39(86.7)$ & \\
\hline & Total & $45(100)$ & $45(100)$ & \\
\hline \multirow{3}{*}{$\begin{array}{l}\text { Smoking, } \\
\mathrm{n}(\%)\end{array}$} & Yes & $8(17.8)$ & $4(8.9)$ & \multirow{3}{*}{$\begin{array}{l}\text { Fisher's Exact test, } \\
p=.35\end{array}$} \\
\hline & No & $37(82.2)$ & $41(91.1)$ & \\
\hline & Total & $45(100)$ & $45(100)$ & \\
\hline \multirow{3}{*}{$\begin{array}{l}\text { History of hospitalization, } \\
\mathrm{n}(\%)\end{array}$} & Yes & $30(67.0)$ & $33(73.3)$ & \multirow{3}{*}{$\begin{array}{l}\text { Fisher's Exact test, } \\
p=.99\end{array}$} \\
\hline & No & $15(33.0)$ & $12(26.7)$ & \\
\hline & Total & $45(100)$ & $45(100)$ & \\
\hline
\end{tabular}


The means of anxiety before the intervention, immediately after the intervention and 30 minutes after the intervention in the groups were presented in Table 2. No statistically significant differences in the level of anxiety in the groups before the intervention were found $(p>.05)$. However, immediately after the intervention and 30 minutes after the intervention, the anxiety level was reduced in the intervention group $(p=$ $.003, \eta=0.09$ ).

According to Table 3, no statistically significant differences in physiological variables between the groups before and after the intervention were reported $(p>.05)$.

Table 2. Comparisons of anxiety between the groups immediately after and 30 minutes after the intervention

\begin{tabular}{|c|c|c|c|c|}
\hline Anxiety & & $\begin{array}{l}\text { Intervention } \\
(\mathrm{n}=45)\end{array}$ & $\begin{array}{l}\text { Placebo } \\
(n=45) \\
\end{array}$ & $\begin{array}{l}\text { Statistical analysis, } \\
p \text {-value }\end{array}$ \\
\hline \multirow{3}{*}{$\begin{array}{l}\text { State Anxiety } \\
\text { (Mean } \pm \text { SD) }\end{array}$} & Before the intervention & $49.43 \pm 11.30$ & $48.22 \pm 10.08$ & \multirow{3}{*}{$\begin{array}{l}\text { Repeated Measures ANOVA, } \\
\mathrm{F}(1,88)=6.71, p=.01, \\
\text { Partial Eta Squared }=0.71, \\
\text { Observed Power }=0.72\end{array}$} \\
\hline & Immediately after the intervention & $35 \pm 9.03$ & $43.91 \pm 11.79$ & \\
\hline & 30 min after the intervention & $35.29 \pm 8.96$ & $43.84 \pm 11.77$ & \\
\hline \multirow{3}{*}{$\begin{array}{l}\text { Trait Anxiety } \\
\text { (Mean } \pm \text { SD) }\end{array}$} & Before the intervention & $48.36 \pm 7.88$ & $49.11 \pm 9.34$ & \multirow{3}{*}{$\begin{array}{l}\text { Repeated Measures ANOVA, } \\
\mathrm{F}(1,88)=8.22, p=.005, \\
\text { Partial Eta Squared }=0.08, \\
\text { Observed Power }=0.81\end{array}$} \\
\hline & Immediately after the intervention & $37.89 \pm 7.24$ & $45.49 \pm 11.55$ & \\
\hline & 30 min after the intervention & $37.93 \pm 7.19$ & $45.58 \pm 11.57$ & \\
\hline \multirow{3}{*}{$\begin{array}{l}\text { Total anxiety } \\
\text { (Mean } \pm \text { SD) }\end{array}$} & Before the intervention & $97.69 \pm 17.37$ & $97.33 \pm 16.45$ & \multirow{3}{*}{$\begin{array}{l}\text { Repeated Measures ANOVA, } \\
\mathrm{F}(1,88)=9.13, p=.003, \\
\text { Partial Eta Squared }=0.09, \\
\text { Observed Power }=0.84\end{array}$} \\
\hline & Immediately after the intervention & $72.89 \pm 15.71$ & $89.40 \pm 21.26$ & \\
\hline & 30 min after the intervention & $73.22 \pm 15.13$ & $89.42 \pm 21.27$ & \\
\hline
\end{tabular}

Table 3. Comparisons of hemodynamic indicators between the groups immediately and 30 minutes after the intervention

\begin{tabular}{|c|c|c|c|c|}
\hline \multicolumn{2}{|c|}{ Hemodynamic indicators } & \multirow{2}{*}{$\begin{array}{l}\begin{array}{l}\text { Intervention } \\
(\mathbf{n}=\mathbf{4 5})\end{array} \\
83.49 \pm 10.77\end{array}$} & \multirow{2}{*}{$\begin{array}{l}\begin{array}{l}\text { Placebo } \\
(\mathbf{n}=\mathbf{4 5})\end{array} \\
83.42 \pm 15.51\end{array}$} & \multirow{4}{*}{$\begin{array}{l}\begin{array}{l}\text { Statistical analysis, } \\
\boldsymbol{p} \text {-value }\end{array} \\
\text { Repeated Measures ANOVA, } \\
\mathrm{F}(1,88)=0.16, \\
p=.90\end{array}$} \\
\hline & Before the intervention & & & \\
\hline HR & Immediately after the intervention & $83.51 \pm 9.98$ & $82.93 \pm 14.35$ & \\
\hline & 30 min after the intervention & $82.87 \pm 11.04$ & $82.51 \pm 14.79$ & \\
\hline \multirow{3}{*}{$\begin{array}{l}\text { RR } \\
(\text { Mean } \pm \mathrm{SD})\end{array}$} & Before the intervention & $19.40 \pm 1.94$ & $19.40 \pm 1.83$ & \multirow{3}{*}{$\begin{array}{l}\text { Repeated Measures ANOVA, } \\
\mathrm{F}(1,88)=0.59 \\
p=.44\end{array}$} \\
\hline & Immediately after the intervention & $18.89 \pm 2.10$ & $19.29 \pm 2.09$ & \\
\hline & 30 min after the intervention & $18.78 \pm 1.46$ & $19.22 \pm 1.59$ & \\
\hline \multirow{3}{*}{$\begin{array}{l}\text { SBP } \\
(\text { Mean } \pm S D)\end{array}$} & Before the intervention & $136.84 \pm 24.62$ & $131.82 \pm 28.25$ & \multirow{3}{*}{$\begin{array}{l}\text { Repeated Measures ANOVA, } \\
\mathrm{F}(1,88)=0.51, \\
p=.47\end{array}$} \\
\hline & Immediately after the intervention & $137 \pm 21.13$ & $133.20 \pm 25.69$ & \\
\hline & 30 min after the intervention & $134.53 \pm 23.73$ & $132.22 \pm 28.27$ & \\
\hline \multirow{3}{*}{$\begin{array}{l}\mathrm{DBP} \\
(\text { Mean } \pm \mathrm{SD})\end{array}$} & Before the intervention & $81.82 \pm 14.94$ & $81.67 \pm 15.99$ & \multirow{3}{*}{$\begin{array}{l}\text { Repeated Measures ANOVA, } \\
\mathrm{F}(1,88)=0.36 \\
p=.84\end{array}$} \\
\hline & Immediately after the intervention & $83.56 \pm 13.29$ & $82.07 \pm 15.61$ & \\
\hline & 30 min after the intervention & $80.33 \pm 15.44$ & $80.24 \pm 15.78$ & \\
\hline \multirow{3}{*}{$\begin{array}{l}\text { MAP } \\
(\text { Mean } \pm \text { SD })\end{array}$} & Before the intervention & $97.93 \pm 19.09$ & $97.47 \pm 19.91$ & \multirow{3}{*}{$\begin{array}{l}\text { Repeated Measures ANOVA, } \\
\mathrm{F}(1,88)=0.10 \\
p=.92\end{array}$} \\
\hline & Immediately after the intervention & $100.02 \pm 16.42$ & $98.78 \pm 20.67$ & \\
\hline & 30 min after the intervention & $97.27 \pm 17.45$ & $97.82 \pm 21.31$ & \\
\hline \multirow{3}{*}{$\begin{array}{l}\mathrm{SPO}_{2} \\
(\text { Mean } \pm \mathrm{SD})\end{array}$} & Before the intervention & $95.16 \pm 3.23$ & $95.38 \pm 3.46$ & \multirow{3}{*}{$\begin{array}{l}\text { Repeated Measures ANOVA, } \\
\mathrm{F}(1,88)=0.36 \\
p=.54\end{array}$} \\
\hline & Immediately after the intervention & $95.31 \pm 2.99$ & $95.64 \pm 2.83$ & \\
\hline & 30 min after the intervention & $95.36 \pm 2.96$ & $95.87 \pm 2.11$ & \\
\hline
\end{tabular}

Note. RR: respiratory rate, HR: heart rate, SBP: systolic blood pressure, DBP: diastolic blood pressure, MAP: mean arterial pressure, $\mathrm{SPO}_{2:}$ oxygen saturation.

\section{DiscuSSION}

The purpose of this study was to investigate the effect of hand reflexology on the anxiety level and physiological variables among female patients with ACS in the CCU.

The results of this study showed that hand reflexology re-

Published by Sciedu Press

duced the anxiety level. In the intervention group, anxiety was decreased in State Anxiety and Trait Anxiety. Also, total anxiety was significantly higher in this group compared to the placebo group, which received the simple touch of hand without the stimulation of reflexology points. These findings were in line with those of previous studies. For 
instance, Hyun et al.'s study on patients with ischemic heart diseases $^{[25]}$ and Heydari et al.'s study on patients with cardiac catheterization showed that hand reflexology reduced anxiety. ${ }^{[27]}$ However, McVicar et al. found that hand reflexology had no significant effect on patients' anxiety. ${ }^{[36]}$

In this study, anxiety reduction was observed in the placebo group, but it was not statistically significant. This change in the anxiety level could be attributed to the 'Hawthorne effect'. When individuals are exposed to monitoring and evaluation, they may show some positive effects of the intervention including anxiety reduction. ${ }^{[37]}$

This study also evaluated the effects of hand reflexology on physiological parameters and reported no significant changes after the intervention. Park et al. found that DBP in the intervention group was significantly reduced, but SBP and HR were not significantly reduced. ${ }^{[38]}$ Hyun showed that hand reflexology influenced anxiety in 54 patients with cardiac ischemia admitted to the CCU and reduced their blood pressure and RR. ${ }^{[25]}$ Contrary to the results of this study, Farahani et al. reported that after hand reflexology in patients before the cataract surgery, changes in blood pressure, HR and RR were reported. ${ }^{[22]}$ In addition, Gunnarsdottir and Jonsdottir et al. did not show any significant changes in other physiological parameters after reflexology massage in patients with chronic heart failure except the reduction of SBP. ${ }^{[39]}$ In five clinical trials, Wang reported some effects of reflexology compared to general massage. ${ }^{[40]}$ Such differences in results can be attributed to different techniques and reflexology spots on hands. Disagreements of specialists in the field of reflexology are confirmed by Jones et al. ${ }^{[30,31]}$ Adib-Hajbaghery et al. believed that any kind of massage can have many effects on physiological parameters. ${ }^{[41]}$ Some experts referred to such changes as adverse effects and believed that at the early stages of hand reflexology, the phenomenon of 'healing crisis' or 'cleansing process' may occur, which is accompanied by some changes in physiological symptoms such as HR. It is believed that this phenomenon occurs when therapeutic interventions improve the body's ability and accumulated waste and poisons are released into the bloodstream. These side effects are reduced after several sessions of therapeutic interventions of complementary therapies; therefore, these interventions should be presented more often to obtain the

\section{REFERENCES}

[1] Huffman JC, Smith FA, Blais MA, et al. Anxiety, independent of depressive symptoms, is associated with in-hospital cardiac complications after acute myocardial infarction. J Psychosom Res. 2008; 65: 557-563. PMid:19027445 https://doi.org/10.1016/j.jp

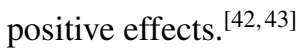

\section{Conclusion}

The use of hand reflexology along with routine care can reduce anxiety in patients with ACS in the CCU. Being simple, low cost, and no need for special devices and instruments, and specialized training are the characteristics of the hand reflexology intervention. In recent years, the use of complementary medicine, including reflexology, has been increased by the public; therefore, healthcare staff including nurses should be educated and trained on complementary medicine to be able to incorporate them into routine nursing practice.

The comparison of the effects of hand reflexology on the anxiety level and physiological variables among male and female patients with ACS should be investigated. Therefore, additional exploratory studies with a greater precision in sampling and various populations such as older people and with the other types of diseases are suggested. Appropriate facilities and educational programs of hand reflexology should be provided for nurses to incorporate hand reflexology in conjunction with others nursing interventions with the aim of relieving patients' anxiety.

In the current study, hand reflexology was applied only at one session, which could be considered a limitation of this study. Therefore, to remove the effect of the 'healing crisis' or 'cleansing process', future studies are suggested to use more sessions of the reflexology intervention. The self-report identity of data collection for the assessment of anxiety was another limitation of this study. It was also impossible to determine whether the reduction of anxiety was solely due to reflexology massage or the 'Hawthorne effect'. Therefore, future studies need to include a control group to be compared with the intervention group in terms of the level of anxiety.

\section{ACKNOWLEDGEMENTS}

This research was supported financially by a grant from Shahed University, Tehran, Iran. The researchers would like to express their gratitude to the participants for taking part in this study.

\section{CONFlicts OF InTEREST Disclosure}

None of the authors have any conflicts of interests about this research. sychores.2008.08.001

[2] McKinley S, Fien M, Riegel B, et al. Complications after acute coronary syndrome are reduced by perceived control of cardiac illness. J Adv Nurs. 2012; 68: 2320-30. PMid:22235775 https: //doi.org/10.1111/j.1365-2648.2011.05933.x 
[3] Luttik ML, Jaarsma T, Sanderman R, et al. The advisory brought to practice: routine screening on depression (and anxiety) in coronary heart disease; consequences and implications. Eur J Cardiovasc Nurs. 2011 Dec; 10(4): 228-33. PMid:20875772 https: //doi.org/10.1016/j.ejcnurse.2010.08.005

[4] Arora D, Anand M, Katyal VK, et al. Anxiety and well-being among acute coronary syndrome patients: overtime. J Indian Acad Appl Psychol. 2010; 36: 79-88

[5] Chen W, Liu G, Yeh S, et al. Effect of back massage intervention on anxiety, comfort, and physiologic responses in patients with congestive heart failure. J Alterna Complement Med. 2013; 19: 464-70.

[6] Tel H, Tel H. The effect of individualized education on the transfer anxiety of patients with myocardial infarction and their families. Heart \& lung: the Journal of Critical Care. 2006; 35(2): 1017. PMid:16543038 https://doi.org/10.1016/j.hrtlng. 200 5.09 .001

[7] Jariani M. Effect of Progressive Muscle Relaxation on Anxiety in Patients with Myocardial Infarction. Lorestan University of Medical Sciences Journal. 2011.

[8] Adib Hajbaghery M, Moradi T, Mohseni R. Effects of a Multimodal Preparation Package on Vital Signs of Patients Waiting for Coronary Angiography. Nurs Midwifery Stud. 2014; 3: E17518.

[9] Watkins LL, Koch GG, Sherwood A, et al. Association of anxiety and depression with all-cause mortality in individuals with coronary heart disease. Journal of the American Heart Association. 2013; 2(2): e000068.

[10] Abdou MH, Engberding N, Wenger NK. Pathophysiology and Management of Myocardial Infarction. Pathophysiology and Pharmacotherapy of Cardiovascular Disease: Springer; 2015: 397-424 p.

[11] Moradi M, Zeighami R. The effect of eye movement desensitization and reprocessing on anxiety in patients with myocardial infarction. Iranian Journal of Psychiatric Nursing. 2013; 1(1): 1-9.

[12] Homayouni K, Zaher H, Borhani F, et al. Effect of tactile touch on stress in patients with myocardial infarction. Journal of Critical Care Nursing. 2013; 5(4): 182-7.

[13] Yeganehkhah MR, mohamadi shab bolaghi F, khankeh HR, et al. The Effects of Slow-Stroke Back Massage on Hypertension in Elderly. Iran Journal of Nursing (Ijn). 2008; 21(54): 73-83. (Persian)

[14] Babashahi M, kahangiL, Babashahi M, et al. Comparing the Effect of Massage Aromatherapy and Massage on Anxiety Level Of the Patients in the Preoperative Period: A clinical trial. Evidence-based Care Journal-Open Access Journal. 2012; 2(2): 19-28.

[15] Hodgson NA, Lafferty D. Reflexology versus Swedish massage to Reduce Physiologic Stress and Pain and Improve Mood in Nursing Home Residents with Cancer: A Pilot Trial. Evid Based Complement Alternat Med. 2012; 1-5 p.

[16] Jenny J, Patricia T, Kathleen I, et al. Is there a specific hemodynamic effect in reflexology? A systematic review of randomized con-trolled trials. J Alternative Complement Med. 2012; 1-10 p.

[17] Jenny J, Patricia T, William L, et al. Reflexology has an acute (immediate) haemodynamic effect in healthy volunteers: A double blind randomised controlled trial. Complement Therap Clin Prac. 2012.

[18] Babaei M, Mousav SH, Tosi G, et al. Predictive Factors of Arterial Blood Oxygen Desaturation during Upper Gastrointestinal Endoscopy in Nonsedated Patients. Journal of Shahid Sadoughi University of Medical Sciences and Health Services. 2008; 16(3): 37-42.

[19] International Institute of Reflexology. The nation's leading Authority. 2012.

[20] Kahangi L, Moeini M, Babashahi M. The effects of reflexology on anxiety levels before coronary artery bypass graft surgery. J Research in Behavioura Science. 2012; 9(5): 163-619.
[21] Torabi M, Salavati M, Ghahri Sarabi A, et al. Effect of foot reflexology massage and Benson relaxation techniques on anxiety and physiological indexes of patients undergoing coronary heart angiography. Nasim-Danesh (Scientific Journal of Hamadan Nursing and Midwifery Faculty), Spring-Summer. 2012; 20(37): 63-71.

[22] Farmahini Farahani M, Shamsikhani S, Norouzi Zamenjani M, et al. The Effect of of hand massage on anxiety and physiological indicators before surgery. CMJA. 2017; 7 (1): 1758-1766.

[23] Nazari R, Ahmadzadeh R, Mohammad S, et al. Effects of hand massage on anxiety in patients undergoing ophthalmology surgery using local anesthesia. JCS. 2012; 1 (3): 129-134. PMid:25276687

[24] Brand LR, Munroe DJ, Gavin J. The effect of hand massage on preoperative anxiety in ambulatory surgery patients. Association of perioperative Registered Nurses Journal. 2013; 97(6): 708-717. PMid:23722035 https://doi.org/10.1016/j.aorn.2013.04 .003

[25] Hyun KS, Lee HY, Kong SC, et al. The Effect of Hand Massage Program on Anxiety in Patients with Ischemic Heart Diease. 2001; 13(2): 340-349.

[26] Mei L, Miao X, Chen H. Effectiveness of Chinese Hand Massage on Anxiety among Patients Awaiting Coronary Angiography: A Randomized Controlled Trial. Eur J Cardiovasc Nurs. 2015; 32(2): 196-203.

[27] Heidari F, Rejeh N, Heravi-Karimooi M, et al. The effect of stress on foot reflex zone therapy on anxiety, hemodynamic parameters of patients waiting for cardiac catheterization. Sci J Hamadan Nurs Midwifery Fac. 2015; 23(2): 63-73.

[28] Wang HL, Keck JF. Foot and hand massage as an intervention for postoperative pain. Pain Manag Nurs. 2004; 5(2): 59-65. https: //doi.org/10.1016/j.pmn.2004.01.002

[29] Cambron JA, Dexheimer J, Coe P. Changes in blood pressure after various forms of therapeutic massage: a preliminary study. $\mathrm{J}$ Altern Complement Med. 2006; 12(1): 65-70. PMid:16494570 https://doi.org/10.1089/acm.2006.12.65

[30] Jones J, Thomson P, Lauder W, et al. Reflexology has no immediate haemodynamic effect in patients with chronic heart failure: A double blind randomised controlled trial. Complementary Therapies in Clinical Practice. 2013; 19: 133-138.

[31] Jones J, Thomson P, Lauder W, et al. Reflexology has an acute (immediate) haemodynamic effect in healthy volunteers: a double-blind randomised controlled trial. Complement Ther Clin Pract. 2012; 18(4): 204-211. PMid:23059433 https://doi.org/10.1016/j. ctcp. 2012.03.006

[32] Byers DC. Better Health with Foot Reflexology: The Ingham Method of Reflexology, Recording for the Blind \& Dyslexic. St. Petersburg: Ingham. 2004.

[33] Spielberger CD, Gorsuch RL, Lusahene RE. Manual for State-Trait Anxiety Inventory. California, Consulting Psychologists Press; 1970

[34] Parsa-Yekta Z, Sharifi-Neiestanak N, Mehran A, et al. Quasi experimental research on anxiety and satisfaction of Patients undergoing open cardiac surgery having intubation. Hayat. 2002; 8(3): 5-12.

[35] Mahram B. Standardization of Spielberger's State Anxiety Inventory in Mashhad, Iran]. Master Thesis Assessment and Measurement in Psychology. Psychology Faculty, Alame Tabatabai University, 1994.

[36] McVicar AJ, Greenwood CR, Fewell F, et al. Evaluation of anxiety, salivary cortisol and melatonin secretion following reflexology treatment: a pilot study in healthy individuals. Complement Ther Clin Pract. 2007; 13(3): 137-145. PMid:17631256 https: //doi.org/10.1016/j.ctcp.2006.11.001

[37] Weeks BP, Nilsson U. Music interventions in patients during coronary angiographic procedures: a randomized controlled study of the 
effect on patients' anxiety and well-being. Eur. J. Cardiovasc. Nurs. 2011; 10 (2): 88-93.

[38] Park MS, Suh MJ. The effect of the hand massage on anxiety of the cancer patients receiving radiation treatment. 1995; 25(2): 316-329.

[39] Gunnarsdottir TJ, Jonsdottir H. Does the experimental design capture the effects of complementary therapy? A study using reflexology for patients undergoing coronary artery bypass graft surgery. J Clin Nurs. 2007; 16(4): 777-785. PMid:17402960 https://doi.org/10.1 $111 / j .1365-2702.2006 .01634 . x$

[40] Wang MY, Tsai PS, Lee PH, et al. The efficacy of reflexology: systematic review. J Adv Nurs. 2008; 62(5): 512-520. PMid:18489444 https://doi.org/10.1111/j.1365-2648.2008.04606.x
[41] Adib-Hajbaghery M, Ali Abasi A, Rajabi-Beheshtabad R, et al. The effects of massage therapy by the patient's relative on vital signs of males admitted in critical care unit. Nurs Midwifery Stud. 2012; 1(1): 16-21. https://doi.org/10.5812/nms. 7903

[42] Romanowski M. Issues that need to be addressed in massage therapy. Nurs Midwifery Stud. 2012; 1(2): 109-110. https://doi.org/10 $.5812 / \mathrm{nms} .8773$

[43] Gunnarsdottir TJ, Jonsdottir H. Healing crisis in reflexology: becoming worse before becoming better. Complement Ther Clin Pract. 2010; 16(4): 239-243. PMid:20920811 https://doi.org/10.1 016/j.ctcp. 2010.01.005 